things than they have ever done, but we think they will have to undergo a certain discipline of conversion, and forget a good deal of interior competitive struggle, and of the outlook connoted thereby, before they qualify for the premier position in the world's markets.

\section{THE CONSTITUTION OF COAL.}

Monograph on the Constitution of Coal. By Dr. M. C. Stopes and Dr. R. V. Wheeler. (Department of Scientific and Industrial Research.) Pp. $5^{8}+$ plates iii. (London: H.M.S.O., 1918.)

\section{Price 2s. net.}

$\mathrm{T}$ is not too much to say that this monograph 1 forms the most important contribution to our knowledge of what coal is, that has yet appeared; the problem has been tackled in the right spirit and by workers with the right kind of experience-namely, by a palæobotanist and a chemist working in conjunction. They themselves define the object of their research as an attempt "to discover what the present actual structure of a bituminous coal most usually is," and they further define what they understand by coal in the following words: "Ordinary coal is a compact stratified mass of 'mummified' plants (which have in part suffered arrested decay to varying degrees of completeness), free from all save a very low percentage of other matter." They themselves admit that this definition is not satisfactory; in particular it suffers from lack of precision, as much depends upon the sense in which the words "very low percentage" are used; it evidently includes lignite, which is perhaps intentional, but it also must include peat, which it was probably intended to exclude.

The monograph naturally falls into two main parts, dealing respectively with the chemical and the structural aspect of coal. The former discusses in much detail the composition of the various component parts that have been more or less completely identified, and relies mainly upon its division into two distinct types of compounds, distinguished as the "cellulosic" and the "resinic," the distinction being based essentially upon the solubility of the latter in pyridine, first discovered by Bedson.

In the latter portion much weight is given to the work of Lomax, which showed that ordinary bituminous coal is a humic accumulation in which, not chiefly wood, but leaves, twigs, fructifications, and other plant fragments preponderate, the term "humic" being used to indicate that the accumulation consisted of the largely undecayed mixed organs of plants. The various distinguishable plant remains are described and discussed, the most important being the woody cells, bark, including cork cells, cuticle, spore-coats and spores, seeds, and soft-walled tissue; it is shown that, with the exception of resin, the cell contents of the plants are but imperfectly preserved in coal.

The authors summarise their researches by stating their opinion that coal consists essentially NO. 2549, VOL. IO2] of a conglomerate of morphologically organised plant tissues, of plant substances devoid of morphological organisation, of the comminuted degradation products of both of these, and of "ulmins" produced therefrom. But it may fairly be said that the value of the work lies not only in this results already attained, but also in the numerous indications that it affords of the directions along which future researches upon this highly complex subject should be conducted. It is to be regretted that the printing has been very badly done, and that numerous clerical errors have been allowed to escape the proof-readers. H. Lours.

\section{ANALYSIS AND GEOMETRY.}

(I) Elementary Mathematical Analysis. By Prof. J. W. Young and F. M. Morgan. Pp. xii + 548. (New York: The Macmillan Co., I9I7.) Price i is. net.

(2) A Course of Pure Geometry, containing a Complete Geometrical Treatment of the Properties of the Conic Sections. By the Rev. Dr. E. H. Askwith. New edition. Pp. xi +284 . (Cambridge: At the University Press, 1917.) Price $7 s .6 d$. net.

(r) THE aim of Messrs. Young and Morgan is very clearly explained in their preface.

Their book is intended for first-year students in universities and colleges, and, without in any way neglecting practical methods and applications, they have properly laid stress upon fundamental ideas such as "function," "continuity," and so on. Thus the student is prepared in due time for more abstract and delicate theories, and preserved from the risk of becoming a mere calculating-machine.

The contents of the book are arranged in five parts. The first is introductory; it deais with the idea of a function and its geometrical representation, and gives a sketch of the theory of rational operations in algebra. Part ii. considers elementary functions, including the simply periodic ones; it also gives a chapter on computation, in which there is an account of the slide rule, and concludes with a chapter on implicit quadratic functions. Part iii. contains the elements of analytical geometry as applied to the straight line, circle, and conic sections. Part iv. comprises chapters on algebraic manipulation, tactic, the binomial theorem, complex numbers, polynomials, theory of equations, and determinants. Part v. deals with functions of two variables, and gives the elements of analytical solid geometry. Finally, there are a set of useful tables, and a detachable page from which a rudimentary slide.rule can be constructed.

The present reviewer has lately been giving lectures on similar, not to say identical, lines; the agreement in aim, choice of topics, and extent of treatment has been practically complete. It is an encouragement to find one's ideas of a suitable elementary college course so independently and strikingly confirmed. We believe that treatises of this kind will greatly help to establish a right 